\title{
Do Stock Prices Impact Consumption and Interest Rate in South Africa? Evidence from a Time- Varying Vector Autoregressive Model*
}

\author{
Goodness C. Aye \\ (aye_goody@yahoo.co.uk) \\ (Department of Economics, University of Pretoria, South Africa) \\ Rangan Gupta \\ (Rangan.Gupta@up.ac.za) \\ (Department of Economics, University of Pretoria) \\ Mampho P. Modise \\ (mamphomodise@yahoo.com) \\ (Department of Economics, University of Pretoria)
}

\begin{abstract}
Abstract: This paper investigates the existence of spillovers from stock prices onto consumption and the interest rate for South Africa using a time-varying vector autoregressive (TVP-VAR) model with stochastic volatility. In this regard, we estimate a three-variable TVP-VAR model comprising of real consumption growth rate, the nominal three-months Treasury bill rate and the growth rate of real stock prices. We find that the impact of a real stock price shocks on consumption is in general positive, with large and significant effects observed at the one-quarter ahead horizon. However, there is also evidence of significant negative spillovers from the stock market to consumption during the financial crisis, at both short and long-horizons. Monetary policy response to stock price shocks has been persistent, and strong especially post-the financial liberalization in 1985, but became weaker during the financial crisis. Overall, we provide evidence of significant time-varying spillovers on consumption and interest rate from the stock market.
\end{abstract}

Keywords: Bayesian Inference, Consumption, Stock Price, Markov Chain Monte Carlo, Monetary Policy, Structural Vector Autoregression, Stochastic Volatility, Time-Varying Paremeter

JEL Classification: C11, C15, C32, E31, E32, E44, E52

\section{Introduction}

The permanent income hypothesis postulated by Friedman (1957), asserts that real stock (asset) price inflation increases the expected lifetime wealth of households and hence, their desired consumption. This is known as the wealth effect. In light of this, there exists wide international evidence suggesting that there are major spillovers from the stock market to consumption, in both advanced and emerging economies (see for example, Lettau and Ludvigson, 2001, 2004; Ludvigson et al., 2002; Apergis and Miller, 2004, 2005a, b, 2006; Rapach and Strauss, 2006, 2007; Sousa, 2008a, 2008b, 2010a, 2010b, 2010c,

\footnotetext{
* We would like to thank Jouchi Nakajima for many helpful comments. The usual disclaimer applies.
} 
2010d; Bostic et al., 2009; Fratzscher and Straub; 2009, 2010; Fratzscher et al., 2010; Singh and Pattanaik, 2010; Zhou, 2010; Afonso and Sousa, 2011a; Carroll et al., 2011; Koivu, 2012; Peltonen et al., 2012; Singh, 2012, and references cited in these studies). As far as South Africa is concerned, to the best of our knowledge, there exists only one study by Das et al., (2011), who, based on a singleequation error-correction model, indicate that real stock prices affect consumption significantly both in the short- and long-runs. ${ }^{1}$ The literature relating to stock prices in South Africa has mainly dealt with the effect of monetary policy on stock prices, largely based on (structural) vector autoregressive (VAR) and at times panel data approaches with South Africa as a country in the panel; with all the studies indicating a negative impact on stock prices (returns) following a contractionary monetary policy. ${ }^{2}$ The lack of studies analysing the impact of stock prices on consumption is quite baffling in South Africa, especially when one accounts for the fact that financial wealth accounts for 49.95 percent of household's total assets and 61.59 percent of household's net worth (South African Reserve Bank, Quarterly Bulletin, 2012).

Besides the fact that stock market spillover could be inflationary if it significantly affects aggregate demand through consumption, the recent financial crisis has once again rekindled the debate on whether central banks should conduct monetary policy in a more active manner to prevent the development of bubbles that can be costly in terms of future output and financial stability (André et al., 2011; Peretti, forthcoming). Further, given the fact that the South African Reserve Bank (SARB) has moved to an official inflation-targeting framework since the first quarter of $2000,{ }^{3}$ there is clearly added value in analyzing this question for the country specifically. Recently, Naraidoo and Ndahiriwe (forthcoming) and Naraidoo and Raputsoane (2010) have developed financial conditions indices (FCI), which include stock prices amongst other financial variables, and have analyzed the importance of the FCI using linear and non-linear Taylor (1993)-type rules in South Africa. These studies tend to show that the SARB has systematically reacted to the FCI; more so during the recent financial crisis. Darracq Pariès and Notarpietro (2008) and Finocchiaro and von Heideken (2009) suggests that trying to address the endogeneity problem in stand-alone monetary policy reaction functions using General Method of Moments (GMM) methods produces biased and dispersed estimates. Thus, there are concerns using single-equation Taylor (1993)-type models. Furthermore, the studies using a FCI, which is a composite of four or five asset-related variables, does not specifically indicate the role of stock prices in the monetary policy reaction functions. To the best of our knowledge, there are only two papers that specifically looks at the behavior of the interest rate in response to stock price movements in South Africa is by BongaBonga (2011) and Muroyiwa (2011). ${ }^{4}$ Bonga-Bonga (2011) assessed the dynamic responses of stock prices on inflation, economic activity and monetary policy using a structural vector error-correction model, and concluded that there is a positive relationship between equity prices and interest rates in South Africa.

\footnotetext{
${ }^{1}$ Using a structural vector error-correction model, Bonga-Bonga (2011) showed that equity prices have a significant impact on economic activity in South Africa. Caporale and Sousa (2011), however, could not find significant wealth effects on consumption for South Africa, with the wealth variable being a composite of real house price, real stock price and real per capita M2.

2 See for example, Small and de Jager (2001), Coetzee (2002), Prinsloo (2002), Durham (2003), Hewson and BongaBonga (2005), Alam and Uddin (2009), Chinzara (2010), Mallick and Sousa (2011), Mangani (2011) and Muroyiwa (2011).

${ }^{3}$ In the February of 2000, the Minister of Finance announced that inflation targeting would be the sole objective of the SARB. Currently, the Reserve Bank's main monetary policy objective is to maintain CPI inflation between the target-band of three to six percent, using discretionary changes in the repo rate as its main policy instrument.

${ }^{4}$ For a detailed international literature review in this regard, the reader is referred to Mishkin and White (2002), Crowder (2006), Neri (2004), Sousa (2008a, 2010d), Bjørnland and Leitemo (2009), Napolitano (2009), Agnello and Sousa (2011a), Iglesias and Haughton (2011) and Bjørnland and Jacobsen (forthcoming).
} 
Similar conclusions were also reached by Muroyiwa (2011) based on a SVAR where shocks were identified using a combination of both short-run and long-run restrictions.

Against this background, the objective of this paper is to not only analyze whether real stock price movements have significant spillover effects on consumption decisions in South Africa, but also, whether stock price shocks result in a simultaneous response in the monetary policy instrument, or whether the response is a delayed one following inflationary pressures due to an increase in aggregate demand resulting, in particular, from the wealth effect of a positive shock in real stock prices. In addition, unlike the sparse literature in South Africa on these two issues, which essentially relies on constant parameter models, we use a time-varying parameter vector autoregressive (TVP-VAR) model with stochastic volatility. TVP-VARs are quite common in the analysis of macroeconomic issues and allow us to capture the time-varying nature of the underlying structure in the economy in a flexible and robust manner (Nakajima, 2011). Therefore, this paper makes the first attempt in the context of South Africa, to analyze the time-varying spillover effect of stock price shocks on consumption and interest setting behavior, with the time-varying framework allowing us to not only identify the general relationship between the variables of interest, but more importantly, enables us to view how these relationships change depending on the underlying macroeconomic structure of the economy.

To the best of our knowledge, this is the first attempt, in the literature, to analyze the spillover effect of real stock prices on consumption and interest rate using a TVP-VAR model. The decision to use South Africa as our country of investigation simply emanates from our familiarity with major structural changes and shifts in monetary policy regimes in the economy over the period of the analysis, and their possible effects on the variables under consideration in the TVP-VAR model. The only other paper that is somewhat related to our study is the work by Baumeister et al., (2008). However, the authors in this paper is more interested in analyzing how the dynamic effects of excess liquidity shocks on economic activity, asset prices and inflation differ over time. They show that the impact varies considerably over time and depends on the source of increased liquidity and the underlying state of the economy. The remainder of the paper is organized as follows: Section 2 discusses the methodology of the TVP-VAR technique. Section 3 lays out the data used. Section 4 presents the results of a stock price shock on consumption and the monetary policy interest setting behavior. Finally, section 5 concludes.

\section{Methodology}

A vector autoregression (VAR), proposed by Sims (1980), has become a popular technique used in econometric analysis and is adaptable to a vast array of economic settings (Baltagi, 2011). In this study, a TVP-VAR model with stochastic volatility is used. The TVP-VAR is common in the analysis of macroeconomic issues and allows us to capture the time-varying nature of the underlying structure in the economy in a flexible and robust manner (Nakajima, 2011). The parameters in the VAR specification are assumed to follow a first order random walk process, thereby incorporating both temporary and permanent changes to the parameters. The inclusion of stochastic volatility is an important aspect in this TVP-VAR model. In many situations, a data-generating process of economic variables seems to have drifting coefficients and shocks of stochastic volatility. In that case, the application of a time-varying parameter model but with constant volatility may result in biased estimations of the time-varying coefficients, since a possible variation of the volatility in disturbances is ignored. The TVP-VAR model with stochastic volatility avoids this misspecification. Although stochastic volatility makes the estimation difficult due to the intractability of the likelihood function, the model can be estimated using Markov Chain Monte Carlo (MCMC) methods in the context of a Bayesian inference.

Following Nakajima (2011), this paper estimates a time-varying parameter VAR model with stochastic volatility of the form: 


$$
y_{t}=c_{t}+B_{1 t} y_{t-1}+\ldots+B_{s t} y_{t-s}+e_{t}, \quad e_{t} \sim N\left(0, \Omega_{t}\right),
$$

for $t=s+1, \ldots, n$, where $y_{t}$ is a $(k \times 1)$ vector of observed variables, $B_{1 t}, \ldots ., B_{s t}$ are $(k \times k)$ matrices of time-varying coefficients, and $\Omega_{t}$ is a $(k \times k)$ time-varying covariance matrix. A recursive identification scheme is assumed by the decomposition of $\Omega_{t}=A_{t}^{-1} \Sigma_{t} \Sigma_{t} A_{t}^{\prime-1}$, where $A_{t}$ is a lower-triangle matrix with diagonal elements equal to one, and $\Sigma_{t}=\operatorname{diag}\left(\sigma_{1 t}, \ldots, \sigma_{k t}\right)$. Let us define $\beta_{\mathrm{t}}$ as the stacked row vector of $B_{1 t}, \ldots ., B_{s t} ; a_{t}$ is the stacked row vector of the free lower-triangular elements of $A_{t}$; and $h_{t}=\left(h_{1 t}, \ldots ., h_{k t}\right)$ where $h_{j t}=\log \sigma_{j t}^{2}$. The time-varying parameters are assumed to follow a random walk process:

$$
\begin{aligned}
& \beta_{t+1}=\beta_{t}+v_{\beta t}, \\
& a_{t+1}=a_{t}+v_{a t}, \\
& h_{t+1}=h_{t}+v_{h t},
\end{aligned} \quad\left(\begin{array}{l}
\varepsilon_{t} \\
v_{\beta t} \\
v_{a t} \\
v_{h t}
\end{array}\right) \sim N\left(0,\left(\begin{array}{cccc}
I & 0 & 0 & 0 \\
0 & \Sigma_{\beta} & 0 & 0 \\
0 & 0 & \Sigma_{a} & 0 \\
0 & 0 & 0 & \Sigma_{h}
\end{array}\right)\right)
$$

for $t=s+1, \ldots, n$, with $e_{t}=A_{t}^{-1} \Sigma_{t} \varepsilon_{t}$ where $\Sigma_{a}$ and $\Sigma_{h}$ are diagonal, $\beta_{s+1} \sim N\left(\mu_{\beta o}, \Sigma_{\beta o}\right)$, $a_{s+1} \sim N\left(\mu_{a o}, \Sigma_{\text {ao }}\right)$, and $h_{s+1} \sim N\left(\mu_{h o}, \Sigma_{\mathrm{ho}}\right) .5$

A Bayesian inference is used to estimate the TVP-VAR models via MCMC methods. The goal of MCMC methods is to assess the joint posterior distributions of the parameters of interest under certain prior probability densities that are set in advance. We assume the following priors, as in Nakajima (2011): $\Sigma_{\beta} \sim I W(25,0.01 I),\left(\Sigma_{\alpha}\right)_{i}^{-2} \sim G(4,0.02),\left(\Sigma_{h}\right)_{i}^{-2} \sim G(4,0.02)$, where $\left(\Sigma_{\alpha}\right)_{i}^{-2}$ and $\left(\Sigma_{h}\right)_{i}^{-2}$ are the $i$-th diagonal elements in $\Sigma_{\alpha}$ and $\Sigma_{h}$ respectively. $I W$ and $G$ denotes the inverse Wishart and the gamma distributions respectively. For the initial set of the time-varying parameter, flat priors are set such that: $\mu_{\beta o}=\mu_{a 0}=\mu_{b o}=0$ and $\Sigma_{\beta o}=\Sigma_{a 0}=\Sigma_{b o}=10 \times I$.

\section{Data}

The data sample covers the quarterly period of 1960:1 until 2011:04. A three-variable TVP-VAR model is estimated, capturing the time-varying nature of the macroeconomic dynamics in the South African economy between real consumption, nominal interest rate and real stock prices. Seasonally adjusted real personal consumption expenditure data is obtained from the official website (www.resbank.co.za) of the SARB, while the three-month Treasury bill rate, the All Share Stock Index and Consumer Price Index (CPI) data, used to convert nominal stock prices into its real counterpart, is derived from the International Financial Statistics of the International Monetary Fund. Based on all the standard unit root tests, namely, Augmented Dickey-Fuller (1981) (ADF), Phillips-Perron (1988) (PP), Dickey-Fuller test with generalized least squares detrending (DF-GLS), the Kwiatkowski, Phillips, Schmidt, and Shin (KPSS) (1992) test; the Elliot, Rothenberg, and Stock (ERS) (1996) point optimal test, the Ng-Perron (2001) modified versions of the PP (NP-MZt) test and the ERS point optimal (NP-MPT) test, real consumption expenditure and real stock prices were found to be non-stationary, so the variables were converted to

${ }^{5}$ For a comprehensive analysis of the TVP-VAR methodology and the estimation algorithm, refer to Nakajima (2011).

Page 4 of 13 
their corresponding growth rates, and denoted as $D C$ and DRSP. The nominal interest rate was found to be stationary at the 10 percent level of significance using ADF, DF-GLS, ERS, NP-MZ $Z_{t}$ and NP-MP tests, and hence, was used in levels, and denoted as TBILL. ${ }^{6}$ The stable ${ }^{7}$ TVP-VAR is estimated based on two lags, as was unanimously suggested by all the popular lag-length tests, namely, the sequential modified LR test statistic, the Akaike information criterion, the Schwarz information criterion, applied to a constant parameter VAR. Accounting for stationarity and lags, our effective sample period start from 1960:04.

\section{Results}

To compute the posterior estimates, we draw $M=50,000$ samples after the initial 10,000 samples are discarded. Table 1 presents the estimates for the posterior means, standard deviations, 95 percent credible intervals ${ }^{8}$, the convergence diagnostics (CD) of Geweke (1992) and the inefficiency factors of selected parameters of the TVP-VAR, computed using the MCMC sample. ${ }^{9}$ Based on the CD statistics, the null hypothesis of the convergence to the posterior distribution in the estimated result is not rejected for the parameters at the 5 percent level of significance. In addition, the efficiency factors are quite low in general. Finally, the 95 percent confidence intervals include the estimated posterior mean for each of the parameters estimated. Therefore, the results show that the MCMC algorithm produces posterior draws efficiently. Figure A, in the appendix, presents the estimation results of the TVP-VAR model with stochastic volatility.

Table 1: Estimation results of select parameters in the TVP-VAR model

\begin{tabular}{|l|r|r|r|r|r|}
\hline Parameter & \multicolumn{1}{l|}{ Mean } & \multicolumn{1}{c|}{ Std Dev. } & \multicolumn{1}{l|}{ 95\% Intervals } & \multicolumn{1}{l|}{ CD } & Inefficiency \\
\hline$\left(\Sigma_{\beta}\right)_{1}$ & 0.0040 & 0.0013 & {$[0.0024,0.0072]$} & 0.645 & 69.72 \\
\hline$\left(\Sigma_{\beta}\right)_{2}$ & 0.0044 & 0.0017 & {$[0.0024,0.0091]$} & 0.419 & 53.99 \\
\hline$\left(\Sigma_{\alpha}\right)_{1}$ & 0.0056 & 0.0017 & {$[0.0034,0.0097]$} & 0.925 & 67.45 \\
\hline$\left(\Sigma_{\alpha}\right)_{2}$ & 0.0056 & 0.0016 & {$[0.0034,0.0097]$} & 0.204 & 57.45 \\
\hline$\left(\Sigma_{h}\right)_{1}$ & 0.2515 & 0.0753 & {$[0.1255,0.4187]$} & 0.565 & 90.1 \\
\hline$\left(\sum_{h}\right)_{2}$ & 0.5182 & 0.0967 & {$[0.3510,0.7288]$} & 0.768 & 28.36 \\
\hline
\end{tabular}

Figure 1 reports the data of the three variables in our analysis (DC, TBILL, and DRSP) in the top panel. The corresponding posterior estimates of stochastic volatility are plotted in the bottom panel. The time-

\footnotetext{
${ }^{6}$ These results are available upon request from the authors.

7 The constant parameter VAR is found to be stable as all roots were found to lie within the unit circle.

8 Bayesian inference uses "credible intervals" as opposed to "confidence intervals" used in the frequentist approach to highlight parameter uncertainty.
}

${ }^{9}$ Geweke (1992) suggests the comparison between the first $n_{0}$ draws and the last $n_{1}$ draws, dropping out the middle draws, to check for convergence in the Markov chain. The CD statistics are computed as follows: $C D=\left(\bar{x}_{0}-\bar{x}_{1}\right) / \sqrt{\hat{\sigma}_{0}^{2} / n_{0}+\hat{\sigma}_{1}^{2} / n_{1}}$, where $\bar{x}_{j}=\left(1 / n_{j}\right) \sum_{i=m_{j}}^{m_{j}+n_{j}-1} x^{(i)}$, with $x^{(i)}$ being the $i$-th draw, and $\hat{\sigma}_{j}^{2} / n_{j}$ is the standard error of $\bar{x}_{j}$ respectively for $j=0,1$. If the sequence of the MCMC sampling is stationary, it converges to a standard normal distribution. We set $m_{0}=1, n_{0}=10000, m_{1}=25001$, and $n_{1}=25000 . \hat{\sigma}_{j}^{2}$ is computed using a Prazen window with bandwidth $\left(B_{m}\right)=500$. The inefficiency factor is defined as $1+2 \sum_{s=1}^{B_{m}} \rho_{s}$, where $\rho_{s}$ is the sample autocorrelation at lag $s$, which is computed to measure how well the MCMC chain mixes. 
series plots consist of the posterior draws on each date. The results show that stochastic volatility of consumption growth is highly volatile during the early period of our sample and peaks around 1985, followed by a general downward trend thereafter. This is intuitive as the financial liberalisation in 1985 following the recommendations of the De Kock Commission led to easy availability of credit which led to a consumption boom. The stochastic volatility of consumption remains low and stable from 1990s. The low stochastic volatility towards the end of the sample period may reflect more certainty in consumption behavior derived from a more stable economic and political environment in South Africa. The Treasury bill rate exhibits two major spikes in stochastic volatility during the financial liberalization of 1985 and around 1999, just before the SARB formally introduced inflation targeting. A minor rise in volatility of the Treasury bill rate is also observed around the first oil price shock in 1973.. Not surprisingly, the real stock returns are found to exhibit the most stochastic volatility, with a major peak around 2008, due to the decline in stock returns following the recent financial crisis. Smaller peaks are observe around the 1973 oil price crisis and the financial liberalization. The significant posterior estimates of the stochastic volatility present in the variables of interest, justifies the use of a TVP-VAR model with stochastic volatility to avoid biased estimation.

\section{Figure1: posterior Estimates for Stochastic Volatility}
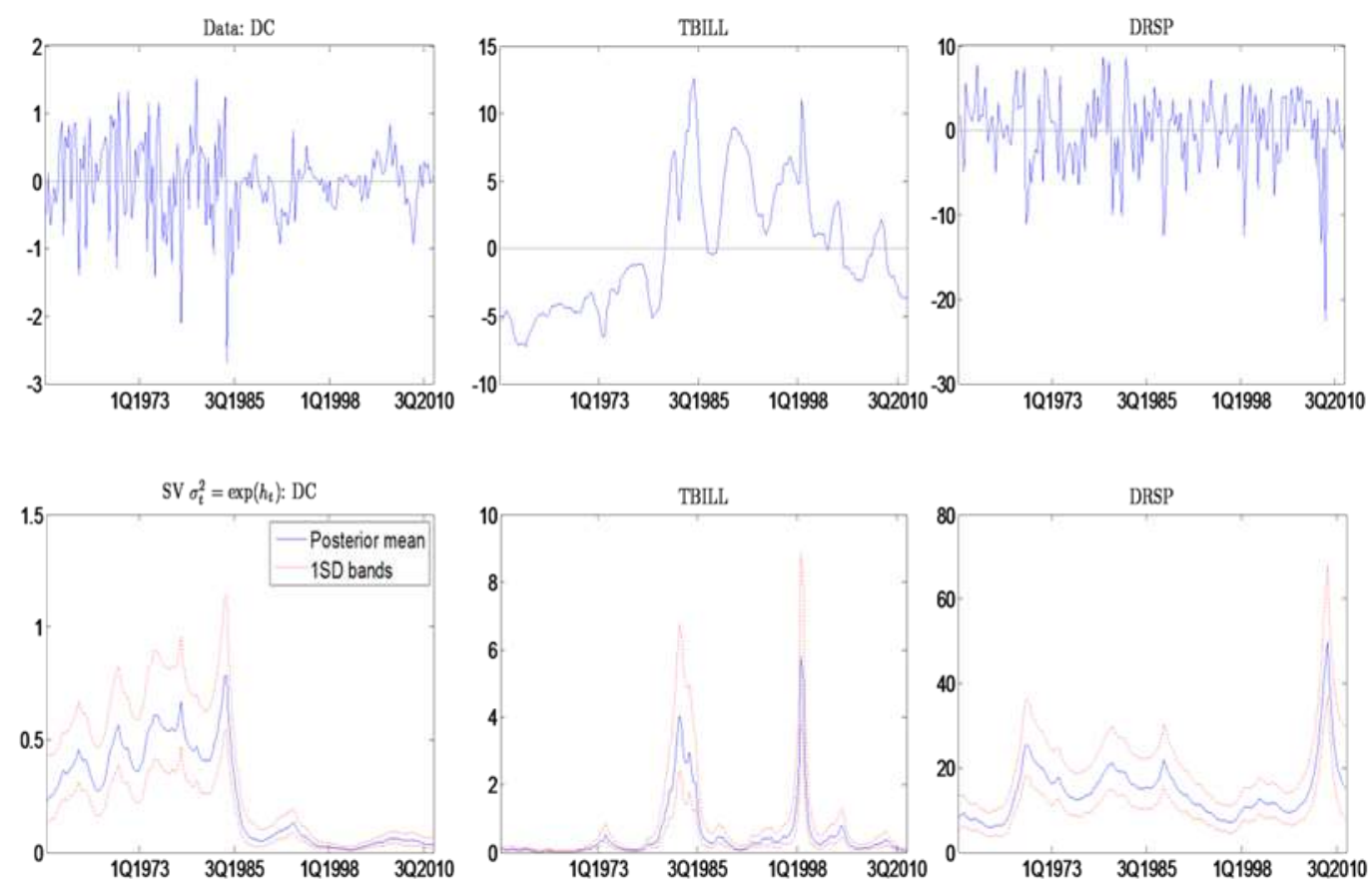

Note: Top panel presents the data values. Bottom panel depicts the posterior mean estimates (solid line) and 95 percent credible intervals (dotted lines) for stochastic volatility of a structural shock.

Impulse responses are used as a tool to capture the macroeconomic dynamics in the estimated VAR system. For a standard constant parameter VAR model, the impulse responses are drawn for each set of two variables, whereas for a TVP-VAR model, the impulse responses can be drawn in an additional dimension, as the responses are computed at all points in time using the time-varying parameters. There are several ways to simulate the impulse responses based on the parameter estimates of the TVP-VAR 
model. Following Nakajima (2011), we compute the impulse responses by fixing an initial shock size equal to the time-series average of stochastic volatility over the sample period, and using the simultaneous relations at each point in time, for considering the comparability over time. In the VAR, the variables are ordered in an attempt to identify the stock price shock using a recursive or Choleski identification scheme, as obtained based on the lower-triangular matrix $A_{\mathrm{t}}$. We order the variables as follows: $D C$, TBILL and DRSP following the literature analyzing asset price shocks on measures of real economic activity and monetary policy behavior. The ordering implies that consumption is not contemporaneously affected by interest rates and real stock prices. The interest rate is assumed to respond contemporaneously to consumption, but with a delay to real stock prices. ${ }^{10}$ Finally, stock prices react contemporaneously to an aggregate demand (consumption) shock and a monetary policy shock. To compute the recursive innovation of the variable, the estimated time-varying coefficients are used from the current date to future periods. Around the end of the sample period, the coefficients are set constant in future periods for convenience. Although a time series of impulse responses for selected horizons or impulse responses for selected periods are often exhibited in the literature, one could draw a threedimensional plot for the time-varying impulse responses.

Figure 2 illustrates the time varying response trajectories at different horizons of one-quarter, fourquarters, eight-quarters and twelve-quarters ahead at each point of the sample, for the three variables of our concern following a shock to real stock price. In the figure, we report the mean of the posterior together with 16th and 84th percentiles.

Figure 2: Impulse responses of the TVP-VAR model following a real stock price shock 1-step ahead
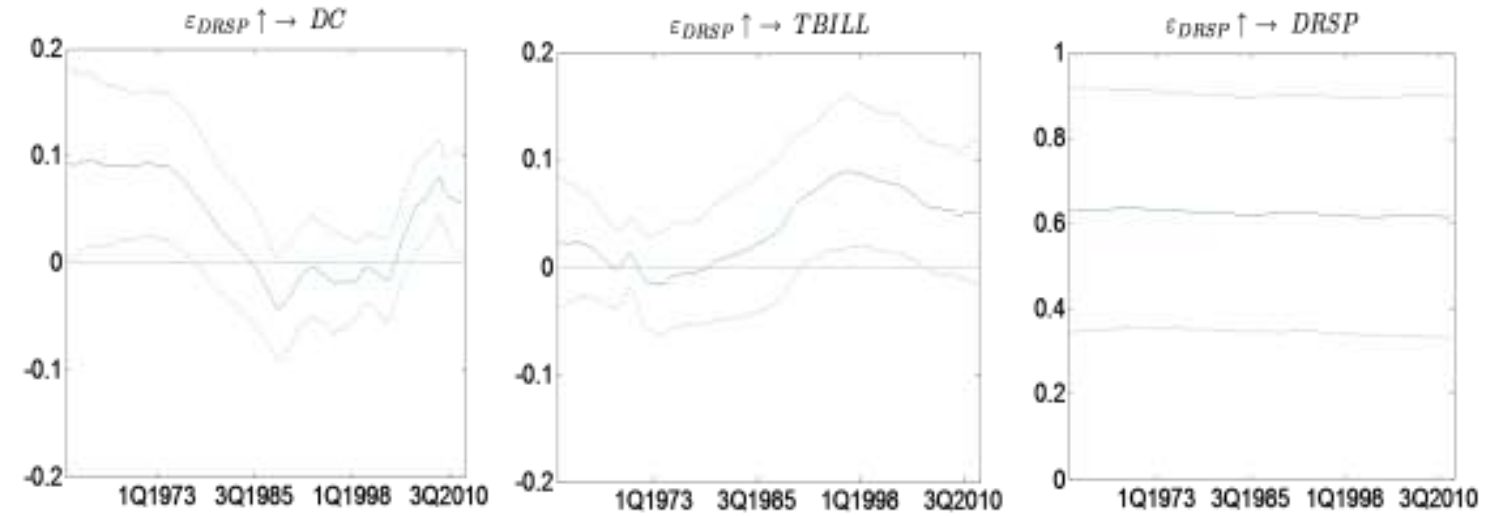

\footnotetext{
${ }^{10}$ Bjørnland and Leitemo (2009)and Bjørnland and Jacobsen (forthcoming) indicate that recursive ordering fail to take into account the possibility of contemporaneous response of monetary policy to stock price movements, and in turn, recommends the usage of short and long-run restrictions in structural VARs to identify shocks. However, Muroyiwa (2011) indicated a delayed response of interest rates to stock price movements even when allowing for contemporaneous relationship between interest rates and stock prices in his constant parameter SVAR, imposing short- and long-run restrictions as suggested by Bjørnland and Leitemo (2009)and Bjørnland and Jacobsen (forthcoming). Hence our ordering of stock prices after interest rate is well-warranted. Having said this, it would be interesting to analyze the possibility of a contemporaneous monetary policy response to stock prices in a TVP-VAR model based on the sign-restriction approach, as popularized recently by Baumeister and Benati (2012) and Baumeister and Peersman (2012, forthcoming).
} 


\section{$\underline{4-\text { steps abead }}$}

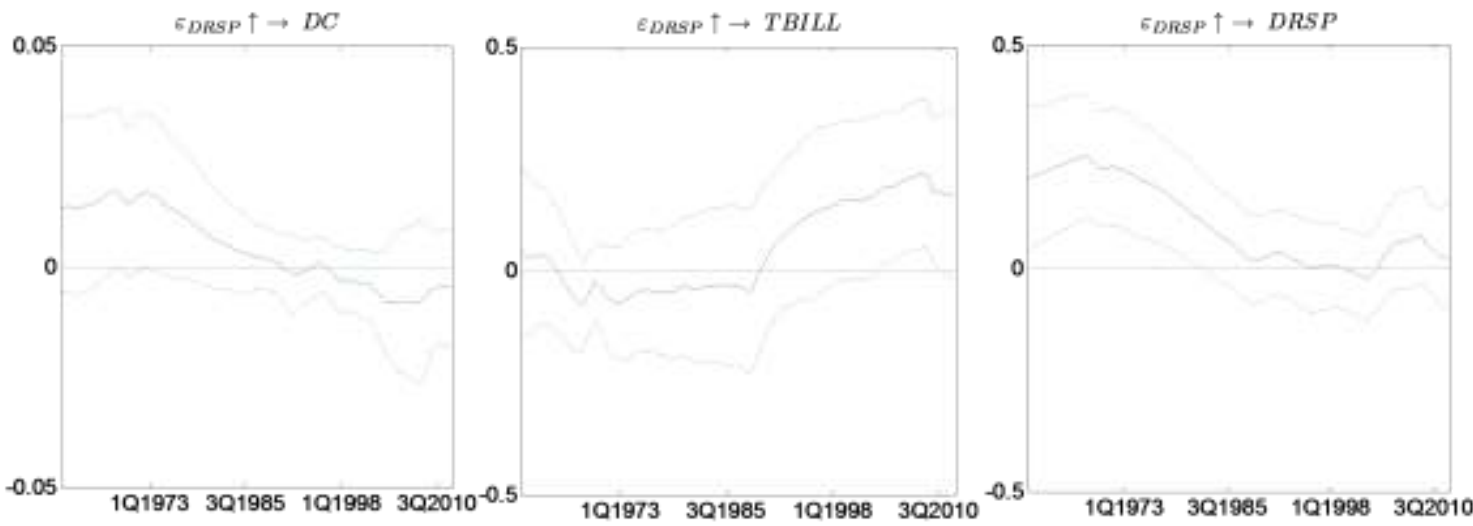

8-steps abead
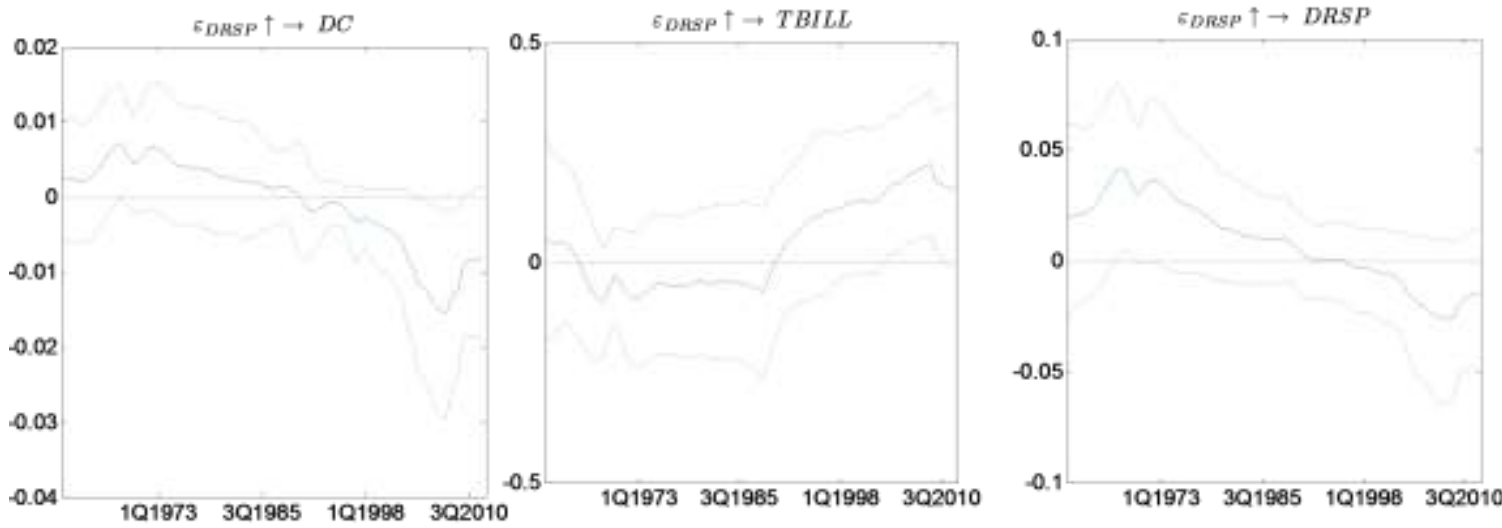

12-steps ahead
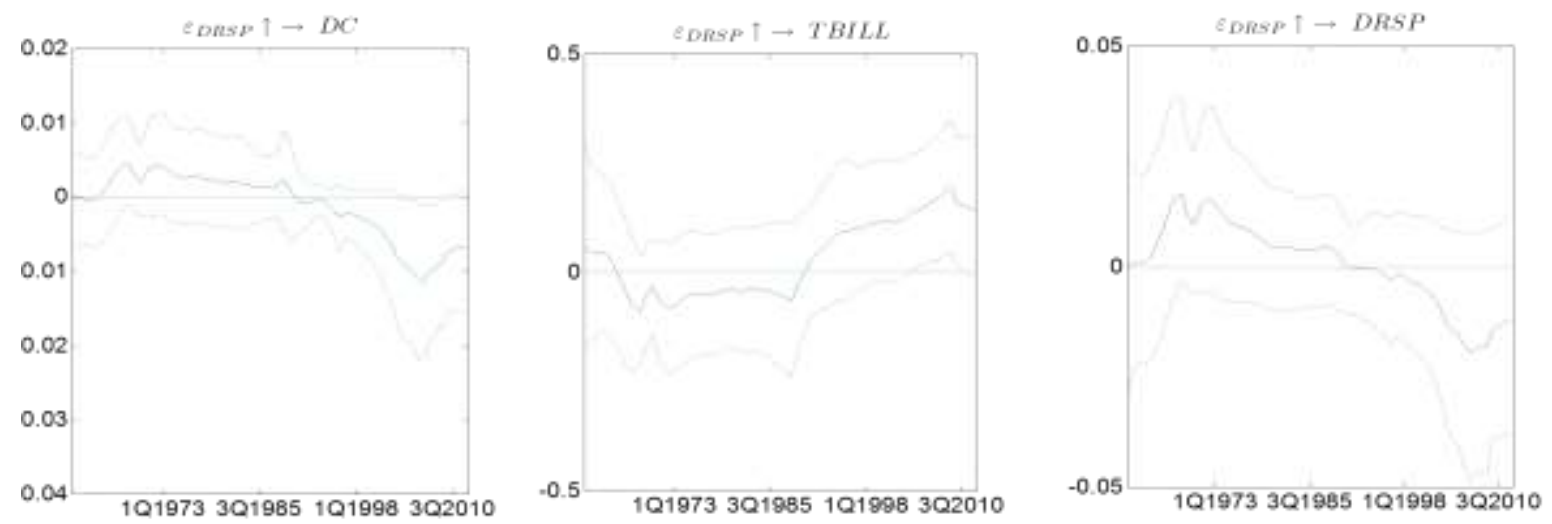

Note: Posterior mean (solid line) and 16 percent and 84 percent quantiles (dotted line)

Following a shock to real stock price, the effect on stock price itself is mostly positive, especially for onequarter and four-quarters ahead horizons. The effect is significant over the entire sample period for the one-quarter-ahead horizon, while the significance for the 4-steps ahead impulse responses lasts till the mid-1980s. Though the effect on stock price is positive for majority of the sample at longer horizons, the effect is not significant at any point of time. Following a positive shock to real stock price, consumption 
in general responds positively, with the effect becoming negative when stock prices become negative. The effect on consumption is primarily significant at the one-quarter ahead horizon, barring the period of mid-1980 till the late 1990, when the effect was insignificantly negative even when real stock prices were significantly positive. Interestingly, at the one-year horizon following the stock price shock, the effect on consumption is hardly significant for the entire period. Negative significant effects on consumption are seen in the latter part of the sample, mainly during the financial crisis, for eight-quarters ahead and twelve-quarters ahead impulse responses, when the stock price in itself was negative, though not significantly. Note that based on the scales of the graphs, the size of the effect on consumption following an increase in real stock prices diminished at longer horizons.

The behaviour of the interest rate following a real stock price increase is quite interesting. For the onequarter ahead impulse responses, the effect is positive in general, barring a short-period in mid to late 1970s, but the effect is only significant post financial liberalization, until the financial crisis. For the oneyear ahead horizon, the impulse responses are initially positive, and then becomes negative, though insignificant, until shortly after financial liberalization. A positive and significant response is observed from there on until the end of the sample, though the effect weakened during the financial crisis. A similar pattern, to the four-quarters ahead horizon, is observed for the eight-quarters ahead and twelve quarters ahead horizons. It seems that the monetary authority started to respond positively to stock price movements more seriously after financial liberalization, with its response reaching a peak just before the financial crisis. The results tend to suggest that for a prolonged period after the first oil price shock till financial liberalization, the SARB was quite happy to allow the stock markets to grow, by lowering interest rate following a positive shock to stock prices. Further, there seems to be quite a bit of persistence in the effect of interest rate movement to stock price behaviour, since the interest rates were positive and significant at longer horizons (eight and twelve) even when the effect on stock price following a shock on itself had become negative. This could possibly indicating the SARB's attempt to keep inflation in check that could have originated from the wealth effect of real stock price increases on consumption. In addition, based on the scales of impulse responses, the effects are bigger at longer horizons, than immediately following the shock on stock prices. ${ }^{11}$

The results suggest that there is high degree of variability in the behaviour of both consumption and interest rates to a stock price shock during different periods and trajectories. The behaviour of stock price following a shock to itself also exhibits different responses depending on the trajectory analysed. All this variability in the behaviour of the variables of our concern, justifies the use of a TVP-VAR with stochastic volatility.

\section{Conclusion}

This paper uses a three variable (growth rate of real consumption, nominal three-months Treasury bill rate and real stock price growth rate) TVP-VAR model with stochastic volatility to analyze the impact of a house price shock on consumption levels and monetary policy for South Africa over the quarterly period of 1966:4-2011:4. We find that the impact of a real stock price shocks on consumption is in general positive, with large and significant effects observed at the one-quarter ahead horizon. However, there is also evidence of significant negative spillovers from the stock market to consumption during the financial crisis, at both short and long-horizons. Monetary policy response to stock price shocks has been persistent and strong, especially post-financial liberalization, but became weaker during the financial crisis.

11 The impulse response functions for a shock to DC and TBILL were found to be in line with standard economic theory; overall, a positive consumption shock (aggregate demand shock) led to a rise in the interest rate and the real stock price, while, a contractionary monetary policy shock reduced consumption and real stock price. These results are available upon request from the authors. 
Overall, we provide not only evidence of significant spillovers on consumption and interest rate from the stock market, but, more importantly, we also highlight the fact that these effects have significantly varied over time, which we would not have been able to capture without the usage of a time-varying model. Given that recent papers by Afonso and Sousa (2011b), Agnello and Sousa (2011b), Castro and Sousa (2012) and Agnello et al., (forthcoming) have analyzed the impact of fiscal policy on asset prices and also the possible feedback of asset prices on setting of fiscal policy, it would be interesting to carry out such analyses for South Africa using a TVP-VAR approach in the future. Since, this would not only allow us to account for possible nonlinearity amongst the variables of interest, but also how the relationship has evolved over time.

\section{References}

Alam, M. and Uddin, G.S. 2009. Relationship between interest rate and stock price: Empirical evidence from developed and developing countries. International Journal of Business and Management, 4(3): 43-51.

Afonso, A. and Sousa, R.M. 2011a. Consumption, wealth, stock and government bond returns: international evidence. The Manchester School, 79(6): 1294-1332.

Afonso, A., and Sousa, R. M., (2011b). What are the effects of fiscal policy on asset markets? Economic Modelling 28, 1871-1890.

Agnello L., Castro, V. and Sousa, R. Forthcoming. How do fiscal policy react to wealth composition and asset prices? Journal of Macroeconomics.

Agnello, L. and Sousa, R.M. 2011a. Can fiscal stimulus boost economic recovery?. Banque de France, Document de Travail No. 325.

Agnello, A., and Sousa, R. M., (2011b). Fiscal policy and asset prices. Bulletin of Economic Research, 1-31.

André, C., Gupta, R. and Kanda, P.T. 2011. Do house prices impact consumption and interest rate? Evidence from OECD countries using an agnostic identification procedure. OECD Economics Department Working Paper No. 947.

Apergis, N. and Miller, S.M. 2004. Consumption asymmetry and the stock market: further evidence. University of Connecticut, Department of Economics, Working Paper No. 2004-19.

Apergis, N. and Miller, S.M. 2005a. Consumption asymmetry and the stock market: New evidence through a threshold adjustment model. University of Connecticut, Department of Economics, Working Paper No. 2005-08.

Apergis, N. and Miller, S.M. 2005b. Resurrecting the wealth effect on consumption: further analysis and extension. University of Connecticut, Department of Economics, Working Paper No. 2005-57.

Apergis, N. and Miller, S.M. 2006. Consumption asymmetry and the stock market: Empirical evidence. Economics Letters, 93: 337-342.

Baltagi, B.H. 2011. Econometrics. $5^{\text {th }}$ ed. New York: Springer.

Baumeister, C., Durinck, E. and Peersman, G. 2008. Liquidity, inflation and asset prices in a time-varying framework for the Euro area. National Bank of Belgium, Working Paper Series, No. 142.

Baumeister, C. and Benati, L. 2012. Unconventional monetary policy and the great recession: estimating the macroeconomic effects of a spread compression at the zero lower bound. Bank of Canada, Working Paper 2012-21.

Baumeister, C. and Peersman, G. 2012. Time-Varying effects of oil supply shocks on the U.S. Economy. Bank of Canada, Working Paper 2012-2.

Baumeister, C. and Peersman, G. (Forthcoming) The role of time-varying price elasticities in accounting for volatility changes in the crude oil market. Journal of Applied Econometrics.

Bjørnland, H.C. and Jacobsen, D.H. Forthcoming. The role of house prices in the monetary policy transmission mechanism in the U.S. Scandinavian Journal of Economics.

Bjørnland, H.C and Leitemo, K. 2009. Identifying the interdependence between US monetary policy and the stock market. Journal of Monetary Economics, 56: 275-282.

Bonga-Bonga, L. 2011. Equity prices, monetary policy and economic activities in south Africa. Economic Society of South Africa Conference, Stellenbosch University, Stellenbosch, South Africa.

Bostic, R., Stuart, G. and Painter, G. 2009. Housing wealth, financial wealth, and consumption: new evidence from Micro Data. Regional Science and Urban Economics, 39(1): 79-89.

Caporale, G.M. and Sousa, R.M. (2011b) Consumption, wealth, stock and housing returns: Evidence from emerging markets. CESifo Working Paper No. 3601; DIW Berlin Working Paper No. 1159; Brunel University, Economics and Finance Working Paper No. 11-14; University of Minho, NIPE Working Paper No. 32/2011.

Carroll, C.D., Otsuka, M. and Slacalek. J. 2011. How large are housing and financial wealth effects? a new approach. Journal of Money, Credit and Banking, 43(1): 55-79. 
Castro, V. and Sousa, R. M., (2012). How do central banks react to wealth composition and asset prices? Economic Modelling 29, 641-653.

Chinzara, Z. 2010. Macroeconomic uncertainty and emerging stock market volatility: the case for South Africa. Economic Research Southern Africa Working Paper No 187.

Coetzee, C.E. 2002. Monetary conditions and stock returns: A South African case study. EconWPA, 0205002.

Crowder, W.J. 2006. The interaction of monetary policy and stock returns. The Journal of Financial Research, (4): 523535

Darracq Pariès, M. and Notarpietro, A. 2008. Monetary policy and housing prices in an estimated DSGE model for the US and the Euro Area. Working Paper 972, European Central Bank.

Das, S., Gupta, R., and Kanda, P.T. 2011. Bubbles in the South African housing market and their impact on consumption. Journal of Real Estate Literature, 19(1):69-91.

Dickey, D. and Fuller, W. 1981. Likelihood ratio statistics for autoregressive time series with a unit root. Econometrica, 49:1057-1072.

Durham, J.B. 2003. Monetary policy and stock prices returns. Financial Analysts Journal, 59(4): 26-35.

Elliot, G., Rothenberg, T.J. and Stock, J.H. 1996. Efficient tests for an autoregressive unit root. Econometrica, 64:813836.

Finocchiaro, D. and Queijo von Heideken, V. 2009. Do Central Banks react to house prices? Riksbank Research Paper 217.

Fratzscher, M. and Straub, R. 2009. Asset prices and current account fluctuations in G7 countries. IMF Staff Papers, 56(3): 633-654.

Fratzscher, M. and Straub, R. 2010. Asset prices, news shocks and the current account. CEPR Discussion Paper No. 8080.

Fratzscher, M. Juvenal, L. and Sarno, L. 2010. Asset prices, exchange rates and the current account. European Economic Review, 54, 643-658.

Friedman, M. 1957. A theory of the consumption function. Princeton University Press, Oxford.

Geweke, J. 1992. Evaluating the accuracy of sampling-based approaches to the calculation of posterior moments, in Bernado, J.M., Berger, J.O., Dawid, A.P. and Smith, A.F.M. (eds), Bayesian Statistics, 4:169-188. New York: Oxford University Press.

Hewson, M. And Bonga-Bonga, L. 2005. The effects of monetary policy shocks on stock returns in South Africa: A structural Vector Error Correction Model. Economic Society of South Africa Conference, Durban, South Africa.

Iglesias, E.M., and Haughton, A.Y. (2011). Interaction between monetary policy and stock prices: a comparison between the Caribbean and the US. Contributed paper at the Conference on the Economy (COTE) 2011 held at the University of the West Indies, St. Augustine, Trinidad and Tobago in October 2011.

Koivu, T. 2012. Monetary policy, asset prices and consumption in China. Economic Systems, 36: 307-325.

Kwiatkowski, D., Phillips, P., Schmidt, P. and Shin, J. 1992. Testing the null hypothesis of stationarity against the alternative of a unit root. Journal of Econometrics, 54:159-178.

Lettau, M. and Ludvigson, S.C. 2004. Understanding trend and cycle in asset values: reevaluating the wealth effect on consumption. American Economic Review, 94: 276-299.

Lettau, M., and Ludvigson, S.C. 2001. Consumption, aggregate wealth, and expected stock returns. Journal of Finance, 56: $815-849$.

Ludvigson, S., Steindal, C., Lettau, M., 2002. Monetary policy transmission through the consumption-wealth channel. Federal Reserve Bank of New York Economic Policy Review, 8: 117-133.

Mallick, K.S. and Sousa, M.R. 2011. Inflationary pressures and monetary policy: Evidence from BRICS economies. Quantitative and Qualitative Analysis in Social Sciences Conference: wmw.qass.org.uk/2011-May_Brunelconference/Mallick.pdf.

Mangani R. 2009. Monetary policy, structural breaks and JSE returns. Investment Analysts Journal, 73: 27-35.

Mishkin, F.S. and White, E.N .2002. U.S. Stock Market Crashes and Their Aftermath: Implications for Monetary Policy. Asset Price Bubbles Conference, Federal Reserve Bank of Chicago and the World Bank, Chicago, April 23.

Muroyiwa, B. 2011. Identifying the interdependence between south Africa's monetary policy and the stock market. Unpublished MSc Thesis, Department of Economics and Economic History Rhodes University, Grahamstown, South Africa.

Nakajima, J. 2011. Time-varying parameter VAR model with stochastic volatility: an overview of methodology and empirical applications. IMES Discussion Paper 2011-09, Bank of Japan.

Napolitano, O. 2009. Is the impact of the ECB monetary policy on EMU stock market returns asymmetric? Studi Economici, 0(97): 145-180.

Naraidoo, R and Raputsoane, L. 2010. Zone-targeting monetary policy preferences and financial market conditions: a flexible non-linear policy reaction function of the SARB monetary policy. South African Journal of Economics, 78(4):400-417.

Naraidoo, R. and Kasai, N. 2010. The opportunistic approach to monetary policy and financial markets. University of Pretoria, Department of Economics, Working paper No 2010-06. 
Naraidoo, R. and Ndahiriwe, K. Forthcoming. Financial asset prices, linear and nonlinear policy rules. An in-sample assessment of the reaction function of the South African Reserve Bank. Journal of Economic Studies.

Neri, S. 2004. Monetary policy and stock prices: theory and evidence. Temi di discussione del Servizio studi, Banca,513 (4).

$\mathrm{Ng}, \mathrm{S}$. and Perron, P. 2001. Lag length selection and the construction of unit root tests with good size and power. Econometrica, 69:1519-1554.

Peltonen, T. A., Sousa, R.M. and Vansteenkiste, I. S. 2012. Wealth effects in emerging market economies. International Review of Economics and Finance, 24(2): 155-166.

Peretti, V., Gupta, R. and Inglesi-Lotz, R. Forthcoming. Do house prices impact consumption and interest rate in South Africa? Evidence from a Time Varying Vector Autoregressive model. Economics, Financial Markets and Management.Phillips, P. and P. Perron. 1988. Testing for a unit root in time series regression. Biometrika, 75:335-346.

Primiceri, G.E. 2005. Time varying structural vector autoregressions and monetary policy. Review of Economi Studies, 72: 821-852.

Prinsloo, J.W. 2002. Household debt, wealth and savings. Quaterly Bulletin, South African Reserve Bank.

Rapach, D. and Strauss, J.K. 2006. The long-run relationship between consumption and housing wealth in the eighth district states. Federal Reserve Bank of St. Louis Regional Economic Development, 2: 140-147.

Rapach, D. and Strauss, J.K. 2007. Habit formation, heterogeneity, and housing wealth affects across U.S. States. Missouri Economics Conference.

Sims, C.A. 1980. Macroeconomics and reality. Econometrica, 48:1-48.

Singh, B and Pattanaik, S. 2010. Should monetary in India respond to movements in asset prices? Reserve Bank of India, Occasional Papers, 31(3) Winter 2010.

Singh, B. 2012. How important in the stock market wealth effect on consumption in India. Empir Econ, 42: 915-927.

Smal, M.M. and De Jager, S. 2001. The monetary policy transmission mechanism in South Africa. South Africa Reserve Bank, Occasional Paper No 16.

Sousa, R.M. 2008a. Financial wealth, housing wealth and consumption. International Research Journal of Finance and Economics, 19:167-191.

Sousa, R.M. 2008b. Wealth effects on consumption. In: Boskins, Arnold P. (Ed.), Consumer Economics: New Research, Nova Science Publishers, New York, 2008, 7-38. Lead article.

Sousa, R.M. 2010a. Consumption, (dis)aggregate wealth and asset returns. Journal of Empirical Finance, 17(4): 606-622.

Sousa, R.M. 2010b. Wealth effects on consumption: evidence from the euro area. Banks and Bank Systems, 5(2): 7887.

Sousa, R.M. 2010c. How do consumption and asset returns react to wealth shocks: evidence from the U.S. and the U.K.. The Empirical Economics Letters, 9(5) May.

Sousa, R.M. 2010d. Housing wealth, financial wealth, money demand and policy rule: Evidence from the Euro area. North American Journal of Economics and Finance 2, 88-105.

South African Reserve Bank 2012. Quarterly Bulletin.

Taylor, J.B. 1993. Discretion versus policy rules in practice. Carnegie-Rochester Conference Series on Public Policy, 39:195214

Zhou, X. 2010. Essays on U.S. State-Level Financial Wealth Data and Consumption Data. Unpublished Dissertation, Johns Hopkins University, October. 


\section{Appendix 1}

Figure A: Estimation results of selected parameters in the TVP-VAR model
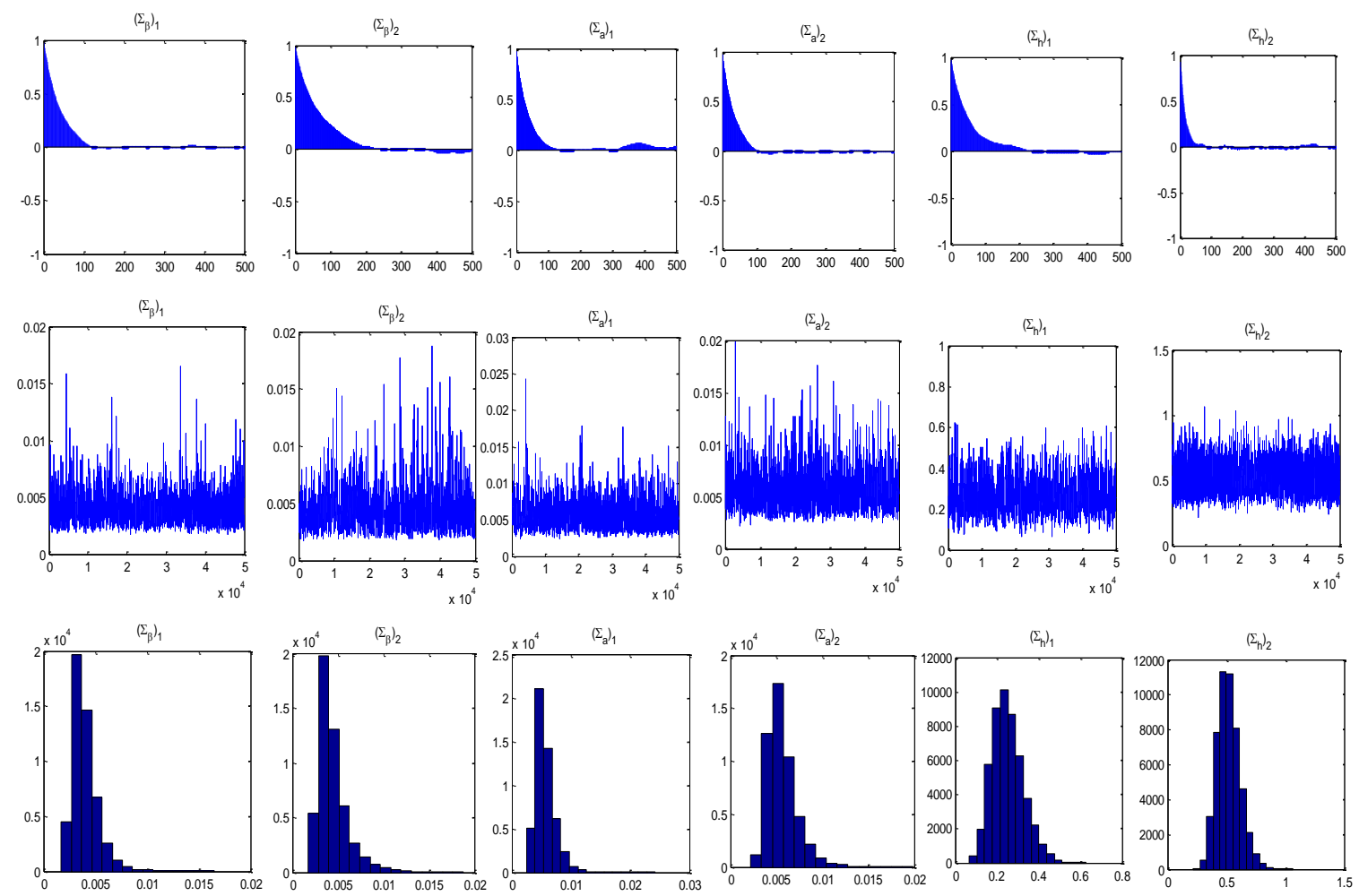

Note: Sample autocorrelations (top panel), sample paths (middle panel), and posterior densities (bottom panel). The estimates of $\Sigma_{\beta}$ and $\Sigma_{a}$ are multiplied by 100 . 